\title{
Elastic behaviour of a model two-phase material
}

\author{
C. L. Hsieh ${ }^{a}$, W. H. Tuan ${ }^{\text {a, }}$, T. T. Wu ${ }^{b}$ \\ a Department of Materials Science and Engineering, National Taiwan University, Taipei, Taiwan ROC \\ ${ }^{\mathrm{b}}$ Institute of Applied Mechanics, National Taiwan University, Taipei, Taiwan ROC
}

Received 18 September 2003; received in revised form 6 February 2004; accepted 13 February 2004

Available online 8 May 2004

\begin{abstract}
Dense $\mathrm{Al}_{2} \mathrm{O}_{3}-\mathrm{NiAl}$ composites containing $0-100 \% \mathrm{NiAl}$ were prepared in the present study, and their elastic properties are determined by a dynamic method. Comparisons are made between the experimental data and several theoretical models. The elastic and shear moduli fall within the Voigt-Reuss bounds and close to the lower bound of the Hashin-Shtrikman (H-S) model. Nevertheless, the bulk modulus and Poisson's ratio of the composites show strong dependence on their microstructural characteristics. As two phases are interconnected in the composites to form an interpenetrating microstructure, the bulk modulus deviates considerably from the Voigt-Reuss and H-S bounds. However, the Poisson's ratio of the composites containing only one continuous phase differs from the model predictions.
\end{abstract}

(c) 2004 Elsevier Ltd. All rights reserved.

Keywords: Composites; $\mathrm{Al}_{2} \mathrm{O}_{3}$; Elastic behaviour

\section{Introduction}

The elastic properties of two-phase materials have been under intensive investigation for many years. ${ }^{1-14}$ Many theoretical models have been developed to describe and predict the elastic properties of two-phase materials. ${ }^{1-11}$ These models all start with the assumption that the two-phase materials are homogeneous on a scale much larger than the size of inclusions, and that the displacements and tractions at the interface between the two phases are continuous. Since the dimension of the specimen considered is much larger than the inclusion size, the shape of the inclusion would make relatively little difference. Among these theoretical models, a number contain one or two arbitrary variables that have to be determined experimentally. ${ }^{3}$ Most models can predict the elastic properties of two-phase materials simply by knowing the elastic properties of each constituent. ${ }^{1,2,4-11}$

Many experimental studies have also been carried out to determine the elastic properties of two phases materials. ${ }^{12-14}$ The predictions made by the theoretical models can always match some experimental data well. ${ }^{12,13}$ However, most of the reported experimental data cover

\footnotetext{
* Corresponding author. Tel.: +886-2-23659800; fax: +886-2-23634562.

E-mail address: tuan@ccms.ntu.edu.tw (W.H. Tuan).
}

only part of the composition range. For example, Doi et al. prepared WC-Co two-phase materials and their elastic properties were measured. However, the metal content in the composites varied from 0 to $45 \mathrm{vol} . \%{ }^{12}$ This may be due to the fact that the composites were prepared by a liquid-phase sintering technique. Too much of liquid Co, if present during sintering might result in serious shape distortion. For another two-phase material, SiC-Al composites, the composition varied from 0 to $40 \% \mathrm{SiC}^{13}$ for the phosphate-alumina composites, it varied from 0 to $33 \%$ alumina. ${ }^{14}$ To compare the experimental data that cover only part of the composition range may lead to biased result. Therefore, there are needs for experimental data that can cover a full composition range.

In the present study, two materials, $\mathrm{Al}_{2} \mathrm{O}_{3}$ and $\mathrm{NiAl}$, with their melting points both higher than $1600{ }^{\circ} \mathrm{C}$ are used. The basic properties of $\mathrm{Al}_{2} \mathrm{O}_{3}$ and $\mathrm{NiAl}$ are shown in Table 1 . The ratios of the elastic modulus and Poisson's ratio of $\mathrm{Al}_{2} \mathrm{O}_{3}$ to those of $\mathrm{NiAl}$ are, respectively, 2.15 and 0.77 . The elastic properties of the two materials are relatively close to each other. Furthermore, $\mathrm{Al}_{2} \mathrm{O}_{3}$ and $\mathrm{NiAl}$ are inert to each other during sintering. ${ }^{15}$ There is no chemical reactions between the two materials and the mutual solubility between the two is negligible. Therefore, the $\mathrm{Al}_{2} \mathrm{O}_{3}-\mathrm{NiAl}$ two-phase material can be treated as a model system to verify the suitability of the theoretical models. 
Table 1

The properties of $\mathrm{Al}_{2} \mathrm{O}_{3}$ and $\mathrm{NiAl}$

\begin{tabular}{lllll}
\hline & $\begin{array}{l}\text { Theoretical } \\
\text { density } \\
\left(\mathrm{g} \mathrm{cm}^{-3}\right)\end{array}$ & $\begin{array}{l}\text { Elastic } \\
\text { modulus } \\
(\mathrm{GPa})\end{array}$ & $\begin{array}{l}\text { Shear } \\
\text { modulus } \\
(\mathrm{GPa})\end{array}$ & $\begin{array}{l}\text { Poisson's } \\
\text { ratio }\end{array}$ \\
\hline $\mathrm{Al}_{2} \mathrm{O}_{3}$ & 3.98 & 401 & 162 & 0.24 \\
$\mathrm{NiAl}$ & 5.95 & 186 & 71 & 0.31 \\
\hline
\end{tabular}

The elastic properties were determined with the ultrasonic technique.

\section{Experimental procedures}

Detailed procedures for the preparation of the $\mathrm{Al}_{2} \mathrm{O}_{3}-\mathrm{NiAl}$ composites can be found elsewhere. ${ }^{15}$ A brief description is given here. Alumina (TM-DAR, mean particle size $=0.2 \mu \mathrm{m}$, Taimei Chem. Co. Ltd., Tokyo, Japan) and various amounts of nickel aluminide $(\mathrm{NiAl}$, mean particle size $=5.9 \mu \mathrm{m}$, Xform Inc., New York, USA) were milled together in ethyl alcohol with an attritor (Model 01-HD, Union Process Inc., USA) for $12 \mathrm{~h}$. The milling media was $\mathrm{ZrO}_{2}$ balls. Sintering was performed by hot pressing at $1450{ }^{\circ} \mathrm{C}$ in a graphite die for $1 \mathrm{~h}$, under an applied pressure of $24.5 \mathrm{MPa}$. The resulting $\mathrm{NiAl}$ content varied from 0 to $100 \%$ with increments of $10 \mathrm{vol} . \%$. The dimensions of the hot pressed specimens were $50 \mathrm{~mm}$ in diameter and roughly $4.5 \mathrm{~mm}$ in thickness. The final density was determined by the water displacement method. Phase identification was performed by X-ray powder diffractometry (XRD) with $\mathrm{Cu}$ $\mathrm{K} \alpha$ radiation. The polished surface was prepared by grinding with a diamond slurry to $6 \mu \mathrm{m}$ and followed by polishing with a silica suspension to $0.05 \mu \mathrm{m}$. The microstructure was observed with scanning electron microscopy (SEM). The inter-connectivity of the NiAl grains in the composites was determined by measuring their electrical resistivity at room temperature. An ultrasonic technique was used to determine the elastic properties of the composites (Pulse Receiver 5055PR and Oscilloscope 9354CM, LeCoroy Co., USA). A frequency of $5 \mathrm{MHz}$ was applied; the longitudinal velocity and transverse velocity within the specimens were determined. Three to five specimens were prepared for each composition.

\section{Results and discussion}

XRD analysis detects no phase other than $\mathrm{Al}_{2} \mathrm{O}_{3}$ and $\mathrm{NiAl}$. The relative density of the $\mathrm{Al}_{2} \mathrm{O}_{3}-\mathrm{NiAl}$ composites varies from 98.5 to $100 \%$ after hot-pressing. Fig. 1 shows the typical microstructures of the $\mathrm{Al}_{2} \mathrm{O}_{3}-\mathrm{NiAl}$ composites. The $\mathrm{NiAl}$ particles were elongated during the mixing process. ${ }^{16}$ The aspect ratio of the $\mathrm{NiAl}$ particles in the sintered composites varied from 3 to 5.4. From Fig. 1a, the NiAl particles in the $\mathrm{Al}_{2} \mathrm{O}_{3}-10 \% \mathrm{NiAl}$ composite are separated from each other. The $\mathrm{Al}_{2} \mathrm{O}_{3}$ particles are isolated particulates in the $\mathrm{Al}_{2} \mathrm{O}_{3}-90 \% \mathrm{NiAl}$ composite (Fig. 1c). Both $\mathrm{Al}_{2} \mathrm{O}_{3}$ and $\mathrm{NiAl}$ are continuous phases within the $\mathrm{Al}_{2} \mathrm{O}_{3}-50 \% \mathrm{NiAl}$ composite, as demonstrated in Fig. 1b. The $\mathrm{Al}_{2} \mathrm{O}_{3}$ and $\mathrm{NiAl}$ are

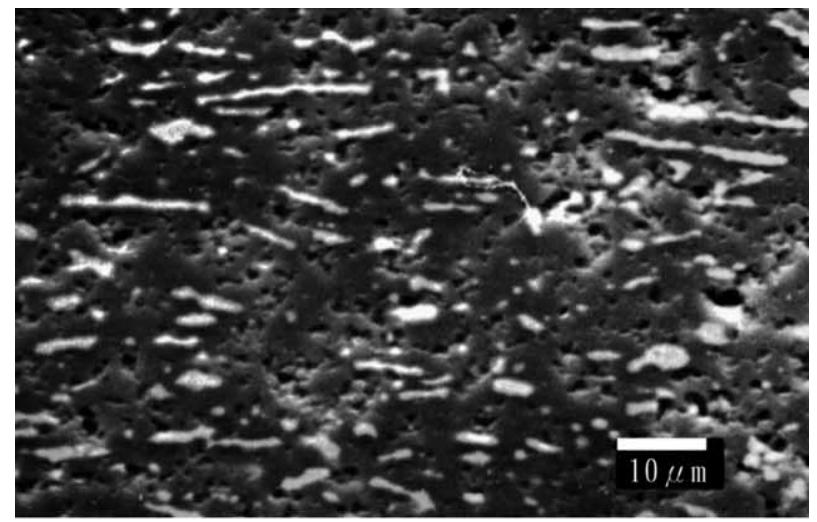

(a)

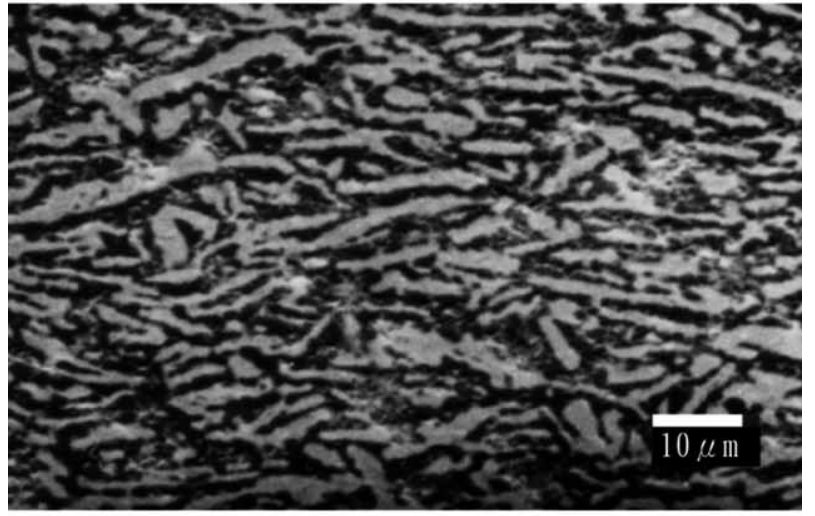

(b)

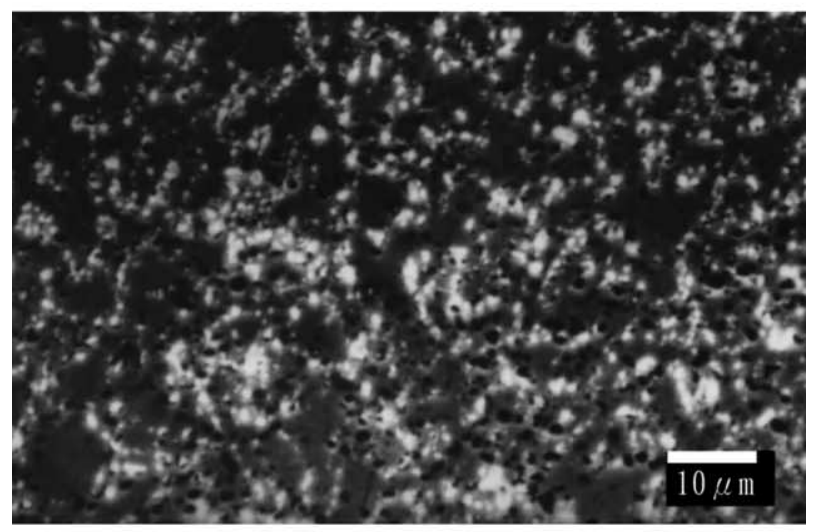

(c)

Fig. 1. Micrographs of (a) $\mathrm{Al}_{2} \mathrm{O}_{3}-10 \% \mathrm{NiAl}$, (b) $\mathrm{Al}_{2} \mathrm{O}_{3}-50 \% \mathrm{NiAl}$ and (c) $\mathrm{Al}_{2} \mathrm{O}_{3}-90 \% \mathrm{NiAl}$ composites. The white particles in (a) and (b) are NiAl, in (c) are $\mathrm{Al}_{2} \mathrm{O}_{3}$ particles. Some $\mathrm{Al}_{2} \mathrm{O}_{3}$ particles in (a) were pulled out during microstructural preparation.

weakly bonded together, ${ }^{15}$ no reaction interphase at the interface was observed.

By taking advantage of the fact that only one phase in the $\mathrm{Al}_{2} \mathrm{O}_{3}-\mathrm{NiAl}$ composites is electrically conducting, the interconnectivity of $\mathrm{NiAl}$ is determined by measuring the electrical resistivity of the composites (Fig. 2). The figure further confirms that the $\mathrm{NiAl}$ particles are separated from each other in the composites containing less than $20 \mathrm{vol} \% \mathrm{NiAl}$. The size of the $\mathrm{Al}_{2} \mathrm{O}_{3}$ particles is one order smaller than 


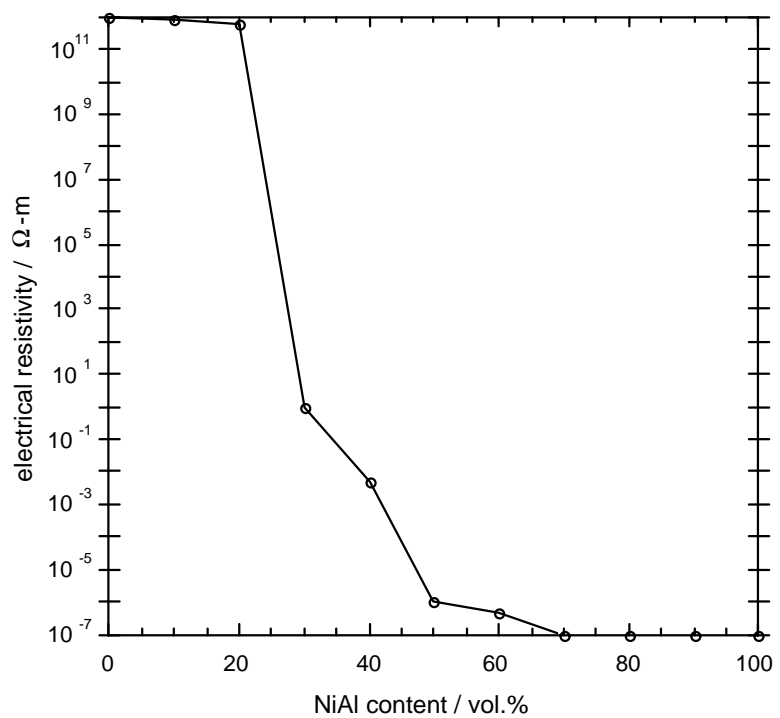

Fig. 2. Electrical resistivity of the $\mathrm{Al}_{2} \mathrm{O}_{3}-\mathrm{NiAl}$ composite as function of NiAl content.

that of the $\mathrm{NiAl}$ grains. The $\mathrm{Al}_{2} \mathrm{O}_{3}$ particles mainly locate at the grain boundaries of the $\mathrm{NiAl}$ (Fig. 1c). The $\mathrm{Al}_{2} \mathrm{O}_{3}$ particles are isolated from each other when the $\mathrm{Al}_{2} \mathrm{O}_{3}$ content is less than $10 \mathrm{vol} . \%$; a continuous $\mathrm{Al}_{2} \mathrm{O}_{3}$ network is formed when the $\mathrm{Al}_{2} \mathrm{O}_{3}$ content is higher than 20 vol.\%. Therefore, the microstructure of the composites within $30-80 \% \mathrm{NiAl}$ composition range forms a three-dimensional interpenetrating structure. Apart from this composition range, the microstructure of the composites is composing of one continuous phase (matrix) and one isolated phase (particle).

Figs. 3 and 4 show the variation of elastic modulus and shear modulus of $\mathrm{Al}_{2} \mathrm{O}_{3}-\mathrm{NiAl}$ composites as a function of $\mathrm{NiAl}$ content, respectively. The data show the mean value of three to five specimens. The standard deviation of each

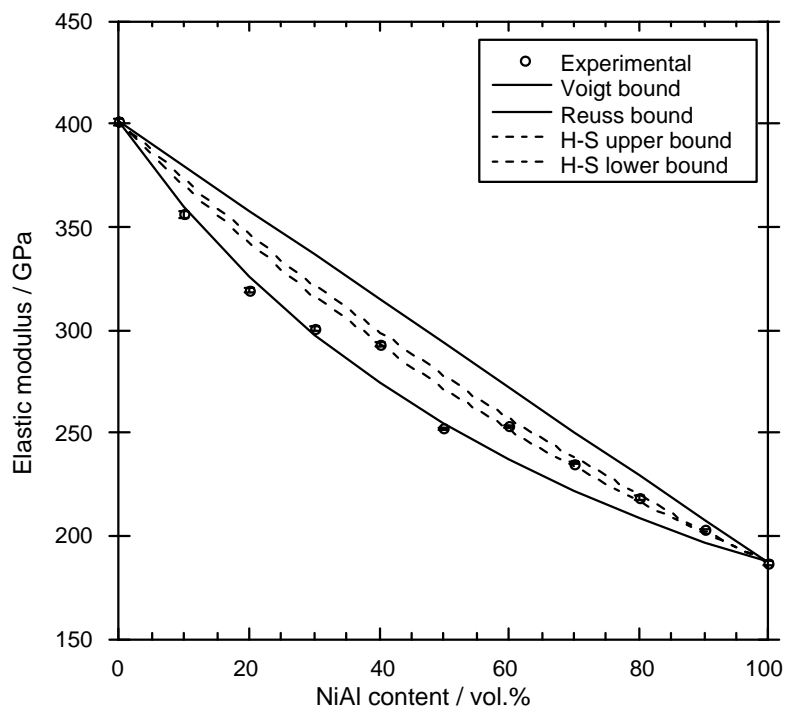

Fig. 3. Elastic modulus of the $\mathrm{Al}_{2} \mathrm{O}_{3}-\mathrm{NiAl}$ composites as function of $\mathrm{NiAl}$ content. The lines are predicted by the Voigt-Reuss and $\mathrm{H}-\mathrm{S}$ models.

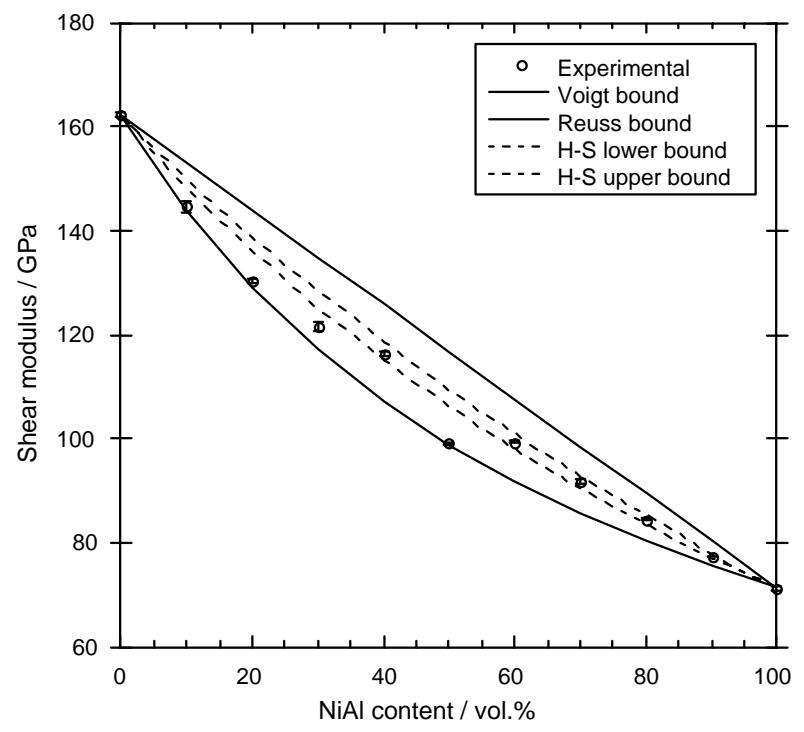

Fig. 4. Shear modulus of the $\mathrm{Al}_{2} \mathrm{O}_{3}-\mathrm{NiAl}$ composites as function of $\mathrm{NiAl}$ content. The lines are predicted by the Voigt-Reuss and H-S models.

mean value is also shown in the figure. Under an uniform strain assumption as proposed long ago by Voigt, the elastic modulus, $E$ of the two-phase material can be estimated as

$E_{\mathrm{c}}^{\mathrm{u}}=E_{\mathrm{a}} V_{\mathrm{a}}+E_{\mathrm{b}} V_{\mathrm{b}}$

with $V_{\mathrm{a}}+V_{\mathrm{b}}=1$, where $V_{\mathrm{a}}$ and $V_{\mathrm{a}}$ are the volume fraction of the two phases. Since the porosity amount in the composites is lower than $1.5 \%$, the effect of pores on the estimated elastic constants is ignored. Under an uniform stress assumption as proposed by Reuss, the elastic modulus of the two-phase material can be expressed

$E_{\mathrm{c}}^{1}=\frac{E_{\mathrm{a}} E_{\mathrm{b}}}{E_{\mathrm{a}} V_{\mathrm{b}}+E_{\mathrm{b}} V_{\mathrm{a}}}$

The superscript of $u$ and 1 stands for upper bound and lower bound, respectively. As pointed out by Hill ${ }^{5}$ neither assumption is correct. The tractions at the interfaces are not in equilibrium under the Voigt condition; the interface could not remain bonded under the Reuss condition. The equality in Eq. (1) is true only when the Poisson's ratio of the two phases is the same. However, the values predicted by Eqs. (1) and (2) are frequently treated as the upper bound and lower bound of the elastic modulus of two-phase material, respectively. ${ }^{17}$ Furthermore, the Poisson's ratios of $\mathrm{Al}_{2} \mathrm{O}_{3}$ and of NiAl are relatively close to each other. The Voigt-Reuss bounds are thus also used in the present study to compare the experimental data, as shown in Figs. 3 and 4.

The Voigt and Reuss bounds are relatively wide apart, and modifications have accordingly been proposed by many researchers. ${ }^{1-11}$ Among these modifications, the Hashin and Shtrikman model ( $\mathrm{H}-\mathrm{S}$ model) has received wide attention. ${ }^{11-14}$ Hashin and Shtrikman treated the system containing one particulate phase and one continuous matrix phase. They employed the "minimum energy" principle 
and introduced bounds on the bulk modulus, $K$ and shear modulus, $G$ as

$K_{\mathrm{c}}^{1}=K_{\mathrm{m}}+\frac{V_{\mathrm{p}}}{\left(1 / K_{\mathrm{p}}-K_{\mathrm{m}}\right)+\left(3 V_{\mathrm{m}} / 3 K_{\mathrm{m}}+4 G_{\mathrm{m}}\right)}$
$K_{\mathrm{c}}^{\mathrm{u}}=K_{\mathrm{p}}+\frac{V_{\mathrm{m}}}{\left(1 / K_{\mathrm{m}}-K_{\mathrm{p}}\right)+\left(3 V_{\mathrm{p}} / 3 K_{\mathrm{p}}+4 G_{\mathrm{m}}\right)}$

$G_{\mathrm{c}}^{1}=G_{\mathrm{m}}$

$+\frac{V_{\mathrm{p}}}{\left(1 / G_{\mathrm{p}}-G_{\mathrm{m}}\right)+\left(6\left(K_{\mathrm{m}}+2 G_{\mathrm{m}}\right) V_{\mathrm{m}} / 5 G_{\mathrm{m}}\left(3 K_{\mathrm{m}}+4 G_{\mathrm{m}}\right)\right)}$

$G_{\mathrm{c}}^{\mathrm{u}}=G_{\mathrm{p}}$

$+\frac{V_{\mathrm{m}}}{\left(1 / G_{\mathrm{m}}-G_{\mathrm{p}}\right)+\left(6\left(K_{\mathrm{p}}+2 G_{\mathrm{p}}\right) V_{\mathrm{p}} / 5 G_{\mathrm{p}}\left(3 K_{\mathrm{p}}+4 G_{\mathrm{p}}\right)\right)}$

The subscripts $m$ and $p$ denote, matrix and particle, respectively. The lower and upper bounds on the elastic modulus can be estimated by using the following equations as

$$
\begin{aligned}
& E_{\mathrm{c}}^{1}=\frac{9 K_{\mathrm{c}}^{1} G_{\mathrm{c}}^{\mathrm{l}}}{3 K_{\mathrm{c}}^{1}+G_{\mathrm{c}}^{1}} \\
& E_{\mathrm{c}}^{\mathrm{u}}=\frac{9 K_{\mathrm{c}}^{\mathrm{u}} G_{\mathrm{c}}^{\mathrm{u}}}{3 K_{\mathrm{c}}^{\mathrm{u}}+G_{\mathrm{c}}^{\mathrm{u}}}
\end{aligned}
$$

The bounds on the Poisson's ratio as modified by Zimmerman are ${ }^{18}$

$\nu_{\mathrm{c}}^{1}=\frac{3 K_{\mathrm{c}}^{1}-2 G_{\mathrm{c}}^{\mathrm{u}}}{6 K_{\mathrm{c}}^{1}+2 G_{\mathrm{c}}^{\mathrm{u}}}$

$v_{\mathrm{c}}^{\mathrm{u}}=\frac{3 K_{\mathrm{c}}^{1}-2 G_{\mathrm{c}}^{\mathrm{u}}}{6 K_{\mathrm{c}}^{\mathrm{u}}+2 G_{\mathrm{c}}^{1}}$

The upper and lower bounds proposed by the H-S model are relatively closer to each other, as demonstrated in Figs. 3 and 4 . Therefore, the $\mathrm{H}-\mathrm{S}$ model provides a more precise expression for the elastic and shear moduli of a two-phase material. The elastic and shear moduli of the NiAl-rich composites are close to the lower bound of the $\mathrm{H}-\mathrm{S}$ predictions. However, the values of the $\mathrm{Al}_{2} \mathrm{O}_{3}$-rich composite are closer to the Reuss bound, Eq. (2), which is also the lowest bound for all the theoretical predictions.

Though the values of elastic and shear moduli fall well within the Voigt and Reuss bounds, the values of bulk modulus deviate considerably from the bounds (Fig. 5). The theoretical predictions also fail to describe the Poisson's ratio of the $\mathrm{Al}_{2} \mathrm{O}_{3}-\mathrm{NiAl}$ composites (Fig. 6). Nevertheless, the fluctuation of the bulk modulus and Poisson's ratio seems to correspond closely to the interconnectivity of microstructure. For example, the bulk modulus remains more of less the same when the two phases are both continuous phases. It suggests that the bulk modulus of the composites with interpenetrating microstructure is no longer sensitive to the

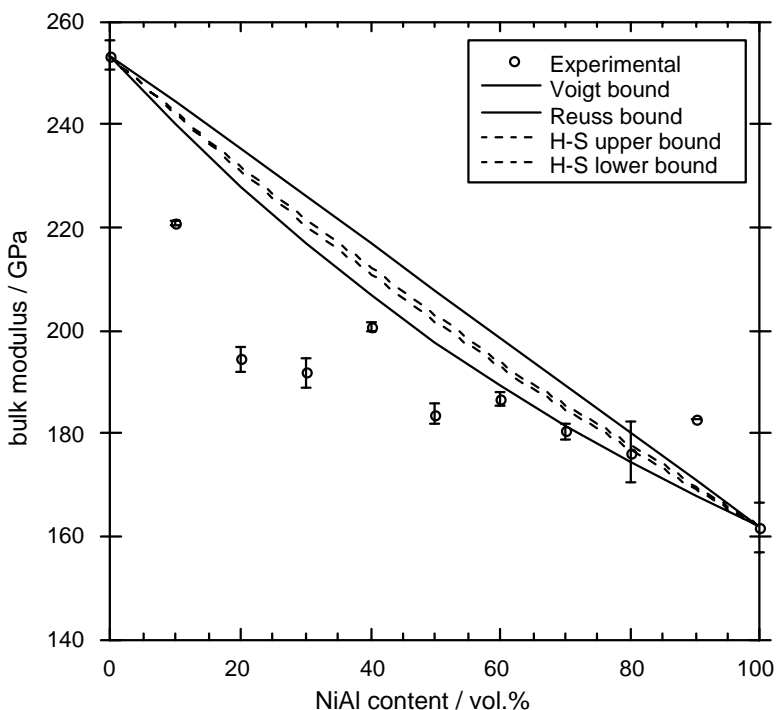

Fig. 5. Bulk modulus of the $\mathrm{Al}_{2} \mathrm{O}_{3}-\mathrm{NiAl}$ composites as function of $\mathrm{NiAl}$ content. The lines are predicted by the Voigt-Reuss and $\mathrm{H}-\mathrm{S}$ models.

amount of each phase. The Poisson's ratio decreases with the increase of NiAl content until the NiAl particles are interconnected. The Poisson's ratio then moves closer to the $\mathrm{H}-\mathrm{S}$ bound while both $\mathrm{Al}_{2} \mathrm{O}_{3}$ and $\mathrm{NiAl}$ are all interconnected. Then, the Poisson's ratio deviates again from the theoretical predictions when the $\mathrm{Al}_{2} \mathrm{O}_{3}$ particles are no longer interconnected.

The formation of a continuous skeleton of one phase is essential for the phase to transfer an external load to another direction. The displacement of one continuous phase is also constrained by another continuous phase in an interpenetrating composite.

The dispersed particle can relatively do little to transfer the load from one direction to another direction. The isolated particles can also impose relatively little constraint

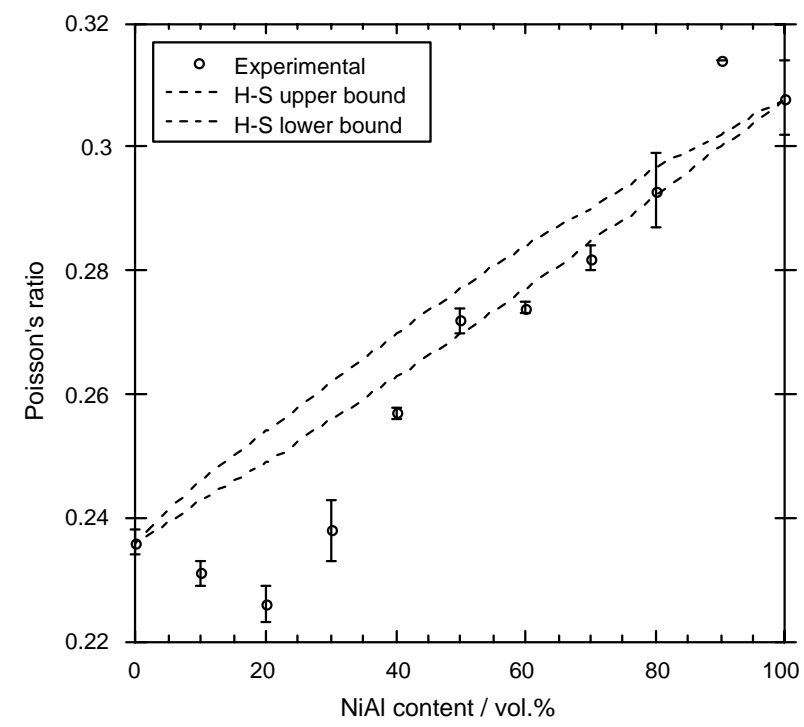

Fig. 6. Poisson's ratio of the $\mathrm{Al}_{2} \mathrm{O}_{3}-\mathrm{NiAl}$ composites as function of $\mathrm{NiAl}$ content. The lines are predicted by the H-S models. 
on the displacement in another direction. Therefore, the interconnectivity of one or two phases in the composite is crucial to its elastic properties. The results also demonstrate that bulk modulus and Poisson's ratio are sensitive parameters to change of microstructure.

It should be noted that the composites prepared in the previous experimental studies ${ }^{12-14}$ are mainly composing of only one continuous phase. Most these experimental data fit well with the predictions made by $\mathrm{H}-\mathrm{S}$ model, which is constructed to describe the two-material containing only one continuous phase. If there was a deviation occurred between the theoretical prediction and previous experimental data, it was attributed frequently to the microstructural complexity of the real composite. ${ }^{9,10}$ For example, finite element analysis has been employed to estimate the shape effect. ${ }^{10}$ However, to the best knowledge of the present authors, the elastic constants of the composite with interpenetrating microstructure have received little attention. It may be has something to do with the fact that a data set across the entire span of composition is not previously available.

\section{Conclusions}

The elastic properties of dense $\mathrm{Al}_{2} \mathrm{O}_{3}-\mathrm{NiAl}$ composite are measured by using an ultrasonic technique. Comparisons are made between experimental data and theoretical models. The elastic and shear moduli fall within the Voigt and Reuss bounds. The bulk modulus and Poisson's ratio deviate considerably from the theoretical predictions. There is thus a need to derive more stringent bounds for the bulk modulus and Poisson's ratio terms. In doing that, the interconnectivity of each phase should be taken into account.

\section{Acknowledgements}

The present work was supported by the National Science Council, Taiwan ROC through contract no. NSC872216-E002-032.

\section{References}

1. Hashin, Z. and Shtrikman, S., A variational approach to the theory of the elastic behaviour of multiphase materials. J. Mech. Phys. Solids 1963, 11, 127-140.

2. Salerno, C. M. and Watt, J. P., Walpole bounds on the effective elastic moduli of isotropic multicomponent composites. J. Appl. Phys. 1986, 60, 1618-1624.

3. Wu, T. T., On the parametrization of the elastic moduli of two-phase materials. J. Appl. Mech. 1965, 32, 211-214.

4. Paul, B., Prediction of elastic constants of multiphase materials. Trans. Metall. Soc. AIME 1960, 218, 36-41.

5. Hill, R., Elastic properties of reinforced solids: some theoretical principles. J. Mech. Phys. Solids 1963, 11, 357-372.

6. Walpole, L. J., On bounds for the overall elastic moduli of inhomogeneous system-I. J. Mech. Phys. Solids. 1966, 14, 155-162.

7. Hashin, Z., Analysis of composite materials. J. Appl. Mech. 1983, 50, 481-505.

8. Davis, L. C., Third order bounds on the elastic moduli of metal-matrix composites. Metall. Trans. A 1991, 22, 3065-3069.

9. Shen, Y.-L., Finot, M., Needleman, A. and Suresh, S., Effective elastic response of two-phase composites. Acta Metall. Mater. 1994, 42, 7797.

10. Ravichandran, K. S., Elastic properties of two-phase composites. $J$. Am. Ceram. Soc. 1994, 77, 1178-1184.

11. Richard, T. G., The mechanical behaviour of a solid microsphere filled composite. J. Compos. Mater. 1975, 9, 108-115.

12. Doi, H., Fujiwara, S., Miyake, K. and Dosawa, Y., A systematic investigation of elastic moduli of WC-Co alloys. Metall. Trans. 1970, 1, 1417-1425.

13. Ibrahim, I. A., Mohamed, F. A. and Lavernia, E. J., Particulate reinforced metal matrix composites-a review. J. Mater. Sci. 1991, 26, $1137-1154$.

14. Kathrina, T., Round, R. and Bridge, B., An investigation of the composition dependence of the elasticity, reaction rate and porosity of orthophosphate bonded ceramics using an ultrasonic double-probe method. J. Phys. D: Appl. Phys. 1991, 24, 1673-1686.

15. Tuan, W. H. and Pai, Y. P., Mechanical properties of $\mathrm{Al}_{2} \mathrm{O}_{3}-\mathrm{NiAl}$ composites. J. Am. Ceram. Soc. 1999, 82, 1624-1626.

16. Tuan, W. H., Chang, S. T., Chou, W. B. and Pai, Y. P., Effect of milling time on the mechanical properties of $\mathrm{Al}_{2} \mathrm{O}_{3}-\mathrm{NiAl}$ composites. Br. Ceram. Trans. 2001, 100, 35-37.

17. Ashby, M. F., Criteria for selecting the components of composite. Acta Metall. Mater. 1993, 41, 1313-1335.

18. Zimmerman, R. W., Hashin-Shtrikman bounds on the Poisson ratio of a composite material. Mech. Res. Commun. 1992, 19, 563569. 